\title{
Computerized Assessment of Coronary Lumen and Atherosclerotic Plaque Dimensions in Three-Dimensional Intravascular Ultrasound Correlated With Histomorphometry
}

\author{
Clemens von Birgelen, MD, Aad van der Lugt, MD, Antonino Nicosia, MD, \\ Gary S. Mintz, MD, Elma J. Gussenhoven, PhD, Evelyn de Vrey, MD, \\ Maria Teresa Mallus, MD, Jos R.T.C. Roelandt, PhD, \\ Patrick W. Serruys, PhD, and Pim J. de Feyter, PhD
}

\begin{abstract}
Intravascular ultrasound (IVUS), which depicts both lumen and plaque, offers the potential to improve on the limitations of angiography for the assessment of the natural history of atherosclerosis and progression or regression of the disease. To facilitate measurements and increase the reproducibility of quantitative IVUS analyses, a computerized contour detection system was developed that detects both the luminal and external vessel boundaries in 3-dimensional sets of IVUS images. To validate this system, atherosclerotic human coronary segments ( $n=13$ ) with an area obstruction $\geq 40 \%(40 \%$ to $61 \%$ ) were studied in vitro by IVUS. The computerized IVUS measurements (areas and volumes) of the lumen, total vessel, plaque-media complex, and percent obstruction were compared with findings by manual tracing of the IVUS images and of the corresponding histologic cross sections obtained at 2-mm increments ( $\mathrm{n}=$ 100). Both area and volume measurements by the con-
\end{abstract}

7 the he natural history and progression or regression of coronary atherosclerosis after pharmacologic and nonpharmacologic interventions have most often bcen asscsscd by quantitative coronary angiography. ${ }^{1-3}$ However, the quantitative angiographic approach permits only the assessment of the luminal silhouette $^{4}$ and indirect estimation of plaque burden. As a result of vessel remodeling, early atherosclerosis remains angiographically undetected until luminal encroachment starts and plaque occupies approximately $40 \%$ of the internal elastic membrane area. Intravascular ultrasound (IVUS) depicts both coronary lumen and vessel wall; measurements can be obtained by manually tracing the luminal and ex-

From the Thoraxcenter, University Hospital Rotterdam-Dijkzigt, Erasmus University Rotterdam, and the Interuniversity Cardiology Institute, Rotterdam, The Netherlands; and the Washington Hospital Center, Washington, DC. This project was partly supported by the Dutch Heart Foundation (Grants 94.016 and 94.006). Dr. von Birgelen was supported by a fellowship of the German Research Sociely (Bonn, Germany). Manuscript received March 21, 1996; revised manuscript received and accepted June 14, 1996

Address for reprints: Pim J. de Feyter, MD, PhD, Department of Coronary Imaging and Intervention, Thoraxcenter, Bd 381, P.O. Box 1738. University Hospital Rotterdam-Dijkzigt, 3000 DR Rotterdam, The Netherlands. tour detection system agreed well with the results obtained by manual tracing, showing low mean betweenmethod differences $(-3.7 \%$ to $0.3 \%$ ) with SDs not exceeding $6 \%$ and high correlation coefficients $(r=0.97$ to 0.99 . Measurements of the lumen, total vessel, plaque-media complex, and percent obstruction by the contour delection system correlated well with histomorphometry of areas $(r=0.94,0.88,0.80$, and 0.88$)$ and volumes $(r=0.98,0.91,0.83$, and 0.91$)$. Systematic differences between the results by the contour detection system and hishomorphometry $(29 \%, 13 \%,-9 \%$, and $-22 \%$, respectively) were found, most likely resulting from shrinkage during tissue fixation. The results of this study indicate that this computerized IVUS analysis system is reliable for the assessment of coronary atherosclerosis in vivo. (c) 1996 by Excerpta Medica, Inc.

(Am J Cardiol 1996;78:1202-1209)

ternal vascular boundaries. ${ }^{6-8}$ To reduce the time and subjectivity of manual tracing, ${ }^{9}$ automated systems for quantitative analysis in 3-dimensional IVUS image sets have been devcloped. ${ }^{10-14}$ As the available systems detect only the lumen, we developed a contour detection algorithm that detects both the luminal and external vascular boundaries of atherosclerotic coronary arteries in 3-dimensional IVUS image sets. ${ }^{15,16}$ This approach allows the quantification of all IVUS images and permits even volumetric assessment which has recently been advocated as a valuable concept in research and clinical practice. ${ }^{17-20}$ To validate this contour detection algorithm, atherosclerotic human coronary explants obtained postmortem or from heart transplant recipients at transplantation were studied with IVUS. Results by the IVUS contour detection system were compared with measurements obtained from manual tracing of the IVUS images and of the corresponding histologic sections.

\section{METHODS}

Human coronary specimens: Thirteen coronary arteries (6 right coronary [RCA], 6 left anterior descending [LAD], and 1 left circumflex [LCX]) with segments of mild to moderate atherosclerosis were 


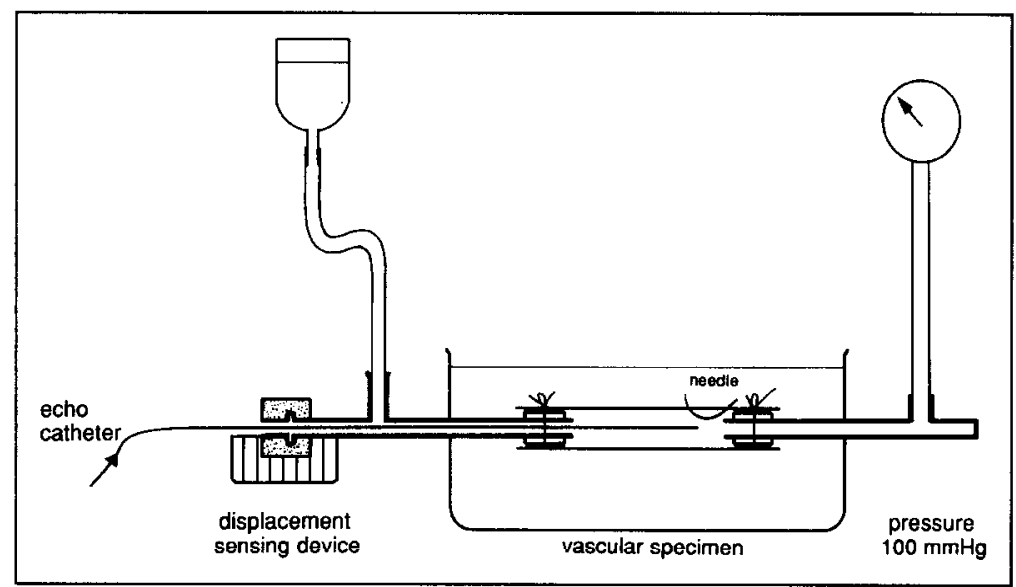

FIGURE 1. The in vitro setup. The ultrasound catheter is advanced through the catheter displacement-sensing device toward the pressurized coronary specimen. A needle attached distally to the artery is used as a reference. The position of the catheter tip in relation to the needle is measured (step size $0.1 \mathrm{~mm}$ ).

explanted postmortem $(\mathrm{n}=6)$ and post-transplantation $(n=4)$ from the hearts of 10 patients ( 7 men, 3 women) with a median age of 51 years (range 39 to 55). Segments with $\leq 1$ major side branch were included in the study. The investigation was approved by the Local Council on Human Research.

In vitro study protocol: For in vitro studies the side branches of the coronary specimen were ligated and the proximal and distal ends were connected to sheaths fixed in a waterbath at $20^{\circ} \mathrm{C}$. A distal reference segment was indicated using a needle. The arteries were pressurized at 100 $\mathrm{mm} \mathrm{Hg}$ by a water reservoir connected to the sidearm of the proximal sheath (Figure 1). The IVUS examination of the pressurized specimen was performed with a mechanical 30-MHz imaging system (Du-MED,

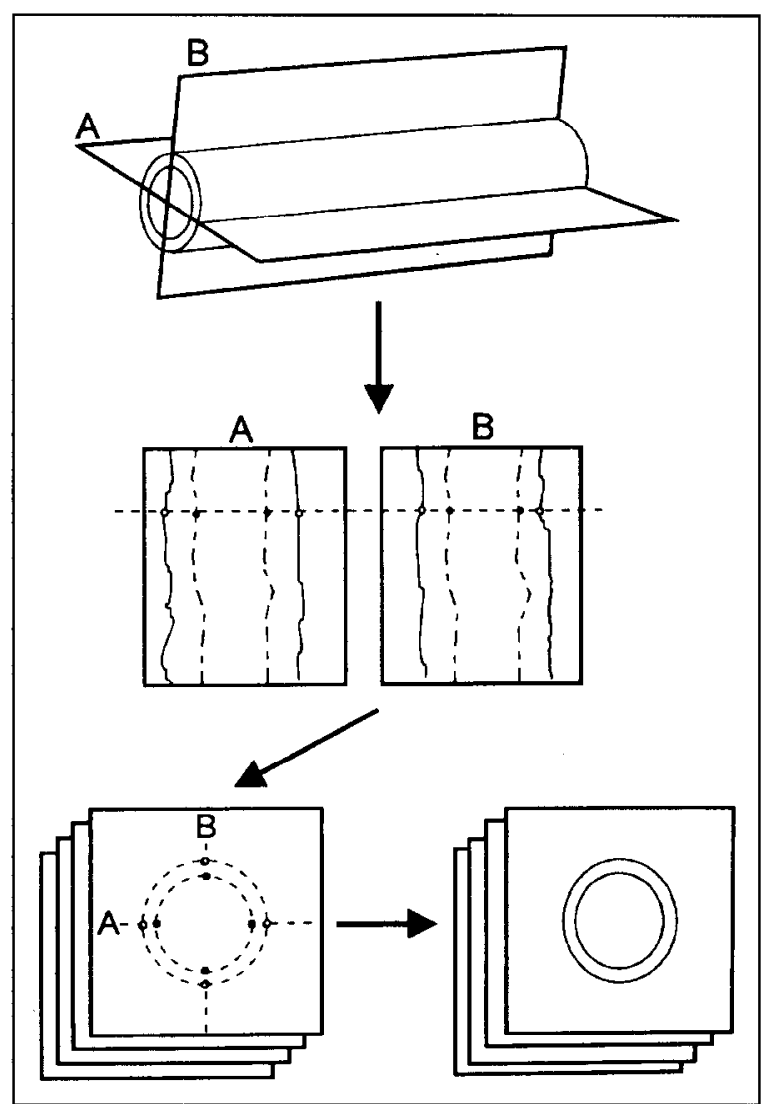

FIGURE 2. Computerized introvascular ultrasound (IVUS) contour detection. Two perpendicular planes running longitudinally along the axis of the artery are used to reconstruct 2 longitudinal sections from the entire sequence of digitized IVUS imoges. The position and rotation angle of the 2 cut planes can be interactively changed to obtain an optimal representation of the coronary segment. Consecutively, the longitudinal contours are automatically detected in these 2 sections and, if required, interactive corrections may be performed. The longitudinal contours intersecting the planes of the transverse images are represented as edge points, guiding the final automated contour detection in the cross-sectional IVUS images by defining the center and the range of the boundary-searching process.
Rotterdam, The Netherlands). The IVUS catheter displacement-sensing device of the Thoraxcenter Rotterdam, which was previously described and applied, ${ }^{21}$ was used to monitor the displacement of the ultrasound catheter tip in steps of $0.1 \mathrm{~mm}$, using the distal needle as the reference. Distance information and IVUS images were automatically mixed and recorded on videotape. This was used as the source for further analyses by the IVUS contour detection system and by manual tracing.

Histologic preparation: The coronary arteries were fixed under pressure $(100 \mathrm{~mm} \mathrm{Hg})$ in $10 \%$ buffered formalin for 2 hours and subsequently decalcified in a standard RDO solution (Apex Inc., Plainfield, Illinois) for 5 hours. The arteries were then processed for routine paraffin embedding. The site of the reference needle was marked using india ink. The 5- $\mu \mathrm{m}$-thick transverse sections were cut at $2-\mathrm{mm}$ intervals perpendicular to the long axis of each specimen, resulting in a total of 100 histologic sections. Staining of the histologic sections was performed with the elastic van Gieson technique. Matching between the IVUS images and the histologic sections was achieved by use of the distance information provided by the displacement-sensing device. Anatomic markers such as side branches or spots of calcium were used to confirm precise matching.

Computerized intravascular ultrasound contour detection system: The analysis program uses the Microsoft Windows operating system on a Pentium (60 $\mathrm{MHz}$ ) personal computer with 16 Mbytes of internal RAM. A frame-grabber (DT-3852; resolution: $800 \times 600 \times 8$ bits) digitizes a user-defined region of interest from a maximum of 200 IVUS images. While a version for clinical application makes use of a motorized pull-back device and digitizes the IVUS images automatically, ${ }^{16}$ selection and digitization of the present in vitro IVUS images was performed by manually choosing the appropriate 


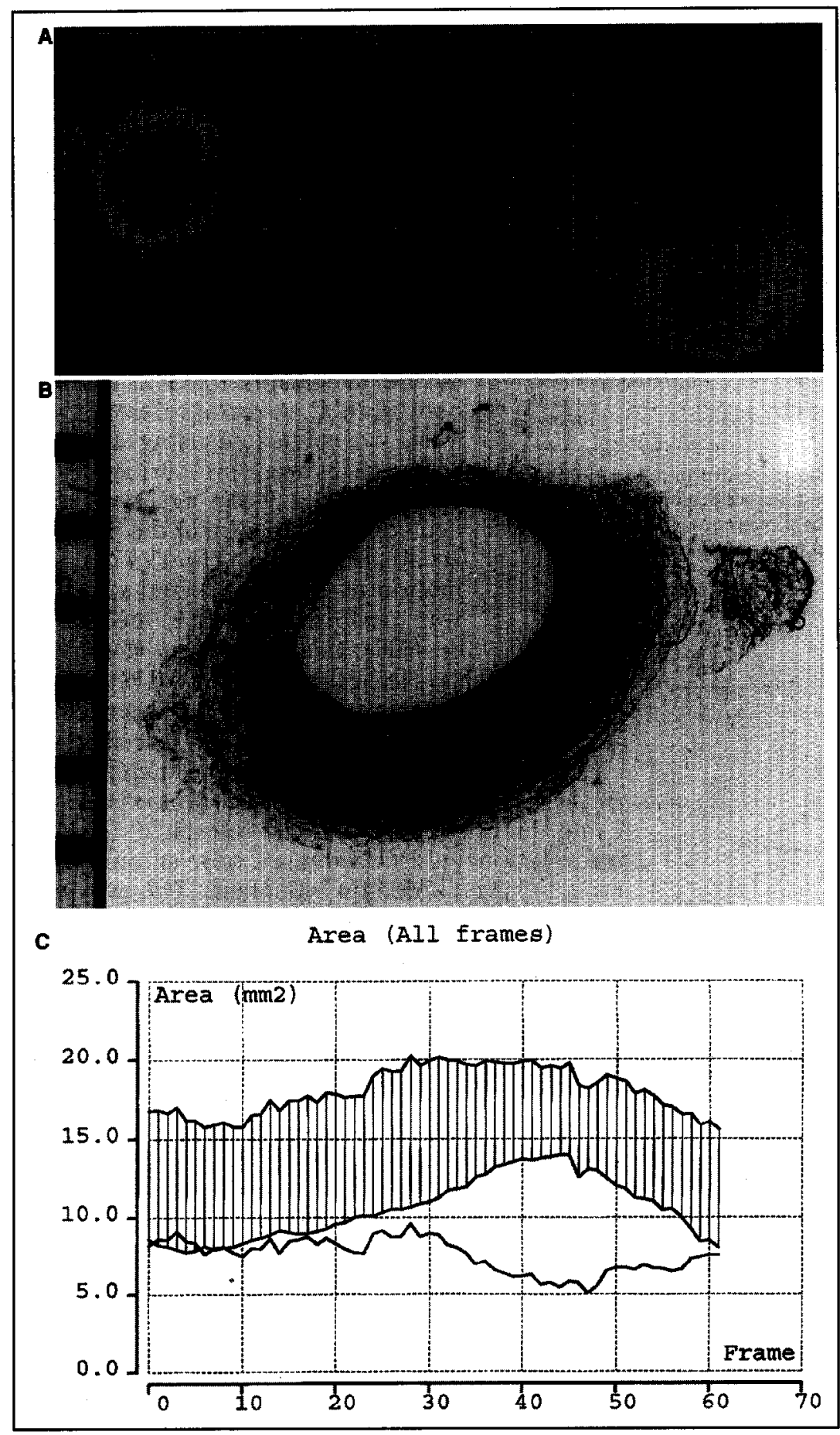

FIGURE 3. Example of the computerized intravascular ultrasound (IVUS) contour detection in vitro. A horizontal cursor can be moved through the perpendicular longitudinal IVUS sections A and B (A, midpane/s) to check the quality of the boundary defection on the cross-sectional IVUS images (left panel). A spatial display of the coronary specimen can be obtained (A, right panel); however, this is not required to quantify the vascular dimen sions. A histologic section (B), showing eccentric plaque formation, corresponds with the ivUS image displayed in the cross-sectional view (A, left panel). The measurements are displayed in an illustrative way $(C)$ : The area values of the lumen (lower line) and total vessel (upper line) form the boundaries of a hatched zone, which represents the plaquemedia complex, and a single line below this zone depicts the absolute area value of the plaque-media complex.

images using the distance information provided by the catheter displacement-sensing device. Images were selected and digitized every $0.2 \mathrm{~mm}$. The algorithm is based on the concept that longitudinal contours facilitate the automated contour detection on the crosssectional IVUS images by defining the center and the range of the boundary-searching process (Figure 2). The position of an individual cross-sectional IVUS image in the longitudinal sections is indicated by a horizontal cursor line which can be used to scroll through the entire series of transverse IVUS images. The detected contours are checked by the analyst, and corrections can be performed by simply pointing with the computer mouse on the correct site and redetecting the contours, using this additional edge information. Corrections are required particularly in images of lower quality and in rapid contour transitions. Whenever the contour of a single slice has been corrected and redetected, the entire data set is updated. As the analysis is performed in a 3dimensional image set, coronary segments can be displayed in a cylindrical format (Figure 3), although this option is not required for the purpose of quantification.

MINIMUM-COST ALGORITHM: Detection of the intimal leading edge and external boundary of the vessel within each image slice is accomplished with the application of a minimum-cost algorithm, previously applied ${ }^{22}$ to single cross-sectional IVUS images. With this approach the digitized IVUS images are resampled according to a radial image reconstruction (64 radii in the cross-sectional images). A cost matrix that represents the edge strength is calculated from the image data. For contour detection of the boundary between lumen and plaque, the cost value is defined by the spatial first derivative. To detect the external boundary contour of the vessel, a pattern matching process by cross correlation is adopted for the cost calculations. Through the cost matrixes a path with the smallest accumulated value is determined by dynamic programming techniques. ${ }^{15}$

VOLUME CALCULATION: Volumes of lumen, total vessel, and plaque-media complex were calculated as: 


\begin{tabular}{|c|c|c|c|c|c|}
\hline & IVUS $|C D|$ & IVUS (MA) & HISTO & $\Delta(C D-M A)$ & $\Delta$ (CD-HISTO $)$ \\
\hline \multicolumn{6}{|l|}{ Area } \\
\hline Lumen $\left(\mathrm{mm}^{2}\right)$ & $13.4 \pm 3.6$ & $13.4 \pm 3.7$ & $10.0 \pm 2.4^{\ddagger}$ & $0.1 \pm 0.3(0.3 \pm 2.5 \%)$ & $3.4 \pm 1.6(28.6 \pm 9.5 \%)$ \\
\hline Total vessel $\left(\mathrm{mm}^{2}\right)$ & $21.0 \pm 4.6$ & $21.3 \pm 4.7^{\ddagger}$ & $18.2 \pm 3.0^{\ddagger}$ & $-0.3 \pm 0.4(-1.1 \pm 2.0 \%)$ & $2.8 \pm 2.4(13.5 \pm 10.2 \%)$ \\
\hline Plaque-media $\left(\mathrm{mm}^{2}\right)$ & $7.6 \pm 2.0$ & $7.9 \pm 2.1^{\ddagger}$ & $8.2 \pm 1.9^{\ddagger}$ & $-0.4 \pm 0.5(-3.1 \pm 6.2 \%)$ & $-0.6 \pm 1.2(-8.6 \pm 18.0 \%)$ \\
\hline$\%$ area obstruction & $36.8 \pm 7.6$ & $37.6 \pm 8.0^{\ddagger}$ & $45.3 \pm 8.1^{\ddagger}$ & $-0.8 \pm 1.8(-2.0 \pm 4.8 \%)$ & $-8.5 \pm 4.1(-22.1 \pm 12.5 \%)$ \\
\hline \multicolumn{6}{|l|}{ Volume } \\
\hline Lumen $\left(\mathrm{mm}^{3}\right)$ & $205.9 \pm 70.4$ & $205.5 \pm 69.6$ & $153.1 \pm 46.7^{\ddagger}$ & $0.5 \pm 1.9(0.2 \pm 0.9 \%)$ & $52.8 \pm 26.2(28.3 \pm 7.2 \%)$ \\
\hline Total vessel $\left(\mathrm{mm}^{3}\right)$ & $322.8 \pm 92.4$ & $327.5 \pm 94.8^{\dagger}$ & $279.2 \pm 71.8^{\ddagger}$ & $-4.8 \pm 5.8(-1.4 \pm 1.5 \%)$ & $43.5 \pm 35.5(13.7 \pm 9.2 \%)$ \\
\hline Plaque-media $\left(\mathrm{mm}^{3}\right)$ & $116.8 \pm 28.8$ & $122.1 \pm 33.3^{\dagger}$ & $126.1 \pm 34.1$ & $-5.3 \pm 6.5(-3.7 \pm 4.3 \%)$ & $-9.3 \pm 14.2(-6.8 \pm 14.2 \%)$ \\
\hline$\%$ volume obstruction & $36.9+6.4$ & $37.8+6.7^{\dagger}$ & $45.3+7.4^{\ddagger}$ & $-0.9 \pm 1.1(-2.4 \pm 2.9 \%)$ & $-8.4 \pm 3.1(-20.5 \pm 7.6 \%)$ \\
\hline
\end{tabular}

$$
V=\sum_{i=1}^{n} A_{i} \cdot H
$$

where $V=$ volume; $A=$ area of lumen, total vessel, or plaque in a certain digitized cross-sectional ultrasound image; $H=$ thickness of the coronary artery slice represented by this digital cross-sectional IVUS image; and $n=$ number of digitized cross-sectional IVUS images encompassing the volume to be measured.

Manual intravascular ultrasound analysis: On the cross-sectional IVUS images that correspond to the histologic sections, a manual tracing of the lumen and the external vessel borders was performed by another independent investigator. This individual was expericnced in the manual IVUS analysis, but did not have knowledge of the results of the computerized analysis. Volumetric data were obtained by Simpson's rule.

Histomorphometric analysis: The histomorphometry was performed with an IBAS 2000 image analysis system (Kontron, Eching, Germany) that allowed manual contour tracing of the luminal contour and the external elastic membrane on digitized microscopic images (magnification $\times 12.5$; pixel size: $0.8262 \times 10^{-2} \mathrm{~mm}$ ) and provided area measurements. Volumetric data were obtained using Simpson's rule.

Data analysis: The quantitative results by all 3 methods included:

- Cross-sectional area of the lumen $\left(\mathrm{mm}^{2}\right)$

- Cross-sectional area of the total vessel $\left(\mathrm{mm}^{2}\right)$

- Cross-sectional area of the plaque-media complex (total vessel area - lumen area) $\left(\mathrm{mm}^{2}\right)$

- Percent area obstruction (plaque-media complex area $\div$ total vessel area) $(\%)$

- Volume of the lumen $\left(\mathrm{mm}^{3}\right)$

- Volume of the total vessel $\left(\mathrm{mm}^{3}\right)$

- Volume of the plaque-media complex (total vessel volume - lumen volume) $\left(\mathrm{mm}^{3}\right)$

- Percent volume obstruction (plaque-media complex volume $\div$ total vessel volume) (\%).

Statistical analysis: Results are given as mean \pm 1 SD. According to Bland and Altman, ${ }^{23}$ the agreement between the computerized IVUS contour de- tection and the manual IVUS measurements and between the computerized IVUS analysis and the histomorphometric measurements were assessed by determining the mean $\pm \mathrm{SD}$ of the betweenmethod differences. Differences were analyzed with the 2-tailed Student $t$ test for paired data analysis. Linear regression analysis was performed to assess the strength of the relation between the methods. $p$ values $<0.05$ were considered statistically significant.

\section{RESULTS}

The coronary segments included in the study were $15.4 \pm 2.8 \mathrm{~mm}$ long (14 to $22 \mathrm{~mm}$ ) and all specimens had a maximum percent area obstruction $>40 \%(47 \% \pm 7 \%$; range $40 \%$ to $61 \%)$ as mcasured by the computerized IVUS analysis system. The minimum percent area obstruction was $29 \% \pm 5 \%$ (range $21 \%$ to $35 \%$ ). Complete volumetric analysis by the computerized contour detection system ( $77 \pm$ 14 images) required significantly less time compared with pure manual contour tracing ( $19 \pm 4$ minutes vs $121 \pm 26$ minutes; $p<0.0001$ ). The results of the computerized IVUS contour detection, manual tracing on the IVUS images, and histomorphometry are presented in Table I.

Contour detection versus manual tracing: The measurements of the lumen, total vessel, plaque-media complex, and percent obstruction by the computerized IVUS contour detection system differed little from the results obtained by manual tracing: The between-method differences (contour detection-manual tracing) were $0.3 \% \pm 2.5 \%,-1.1 \% \pm 2.0 \%$, $-3.1 \% \pm 6.2 \%$, and $-2.0 \% \pm 4.8 \%$ for the area measurements, and $0.2 \% \pm 0.85 \%,-1.4 \% \pm 1.5 \%$, $-3.7 \% \pm 4.3 \%$, and $-2.4 \% \pm 2.9 \%$ for the volume measurements, respectively. Correlations between the area $(r=0.97$ to 0.99$)$ and volume $(r=0.99)$ measurements obtained by both methods were high (Figures 4 and 5).

Contour detection versus histomorphometry: Measurements of the plaque-media complex and percent obstruction by the contour detection system were lower $(\mathrm{p}<0.0001)$ than by histomorphometry (Table I), whereas the measurements of the lumen and total 

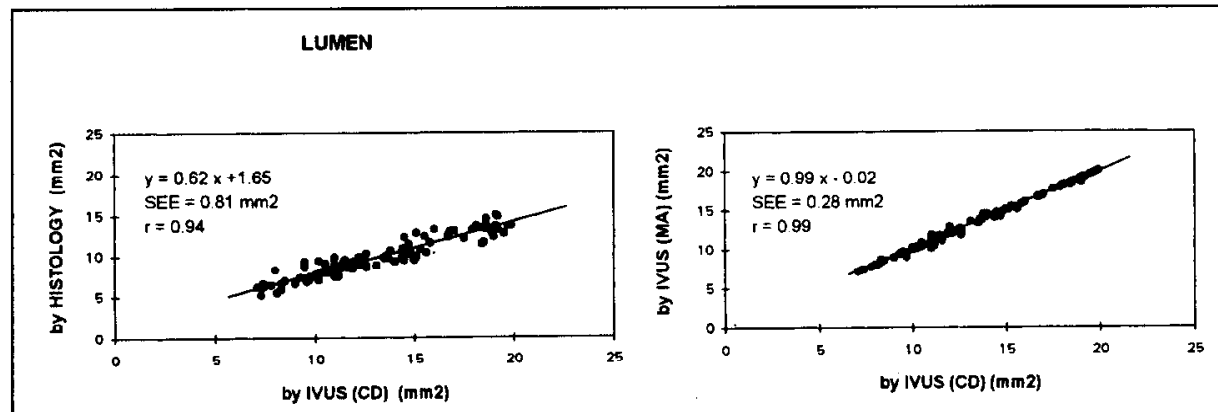

TOTAL VESSEL
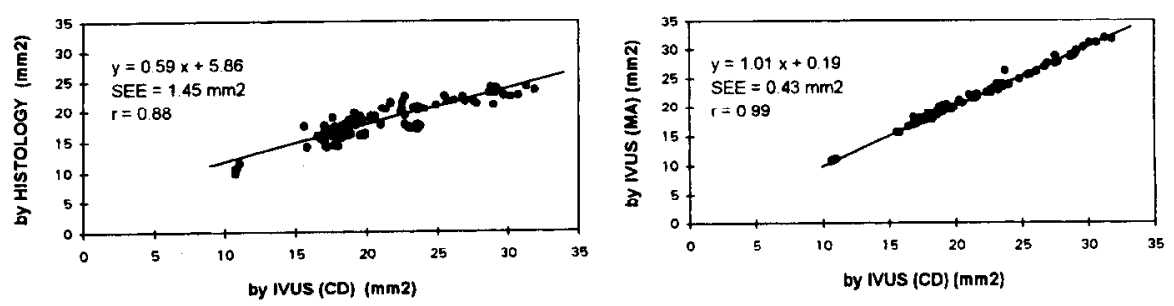

FIGURE 4. Correlations between the area measurements. The results of linear regression analyses are displayed, comparing the measurements of the lumen, total vessel, plaquemedia complex, and percent area obstruction provided by the computerized intravascular ultrasound (IVUS) contour detection (CD) method and manual tracing (MA) on the IVUS images (right panels), and morphometry on the histologic sections (left panels).

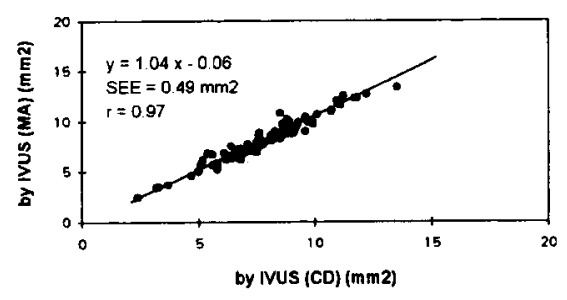

\%-AREA OBSTRUCTION
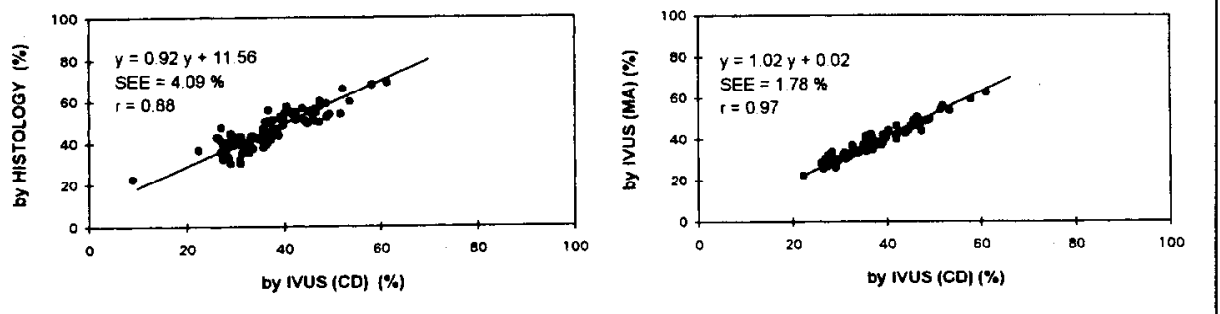

vessel dimensions by the IVUS contour detection system were significantly higher than the histomorphometric results $(p<0.0001)$. The between-method differences (contour detection vs histomorphometry) of the lumen, total vessel, plaque-media complex, and percent obstruction were $29 \% \pm 10 \%, 14 \% \pm$ $10 \%,-9 \% \pm 18 \%$, and $-22 \% \pm 13 \%$ for area measurements, and $28 \% \pm 7 \%, 14 \% \pm 9 \%,-7 \% \pm$ $14 \%$, and $-21 \% \pm 8 \%$ for volumetric measurements, respectively. High correlations (Figures 4 and 5) were found for the area ( $r=0.80$ to 0.94$)$ and volume ( $\mathrm{r}=0.83$ to 0.98 ) measurements by both methods.

\section{DISCUSSION}

In the present study histomorphometric validation of a computerized IVUS analysis system was performed by comparing the results obtained by the computerized IVUS analysis system both with the measurements made by manual contour tracing of the IVUS images and with the corresponding histomorphometric results. The key findings of this study are that (1) the computerized IVUS measurements of areas and volumes are in excellent agreement with the measurements obtained by manual tracing on the IVUS images, and (2) there is a good correlation betweeen measurements obtained from the computerized IVUS analysis and histomorphometry. The good correlation between the results provided by the IVUS contour analysis system and histomorphometry demonstrates the reliability of the computerized approach in performing both area and volume measurements. 


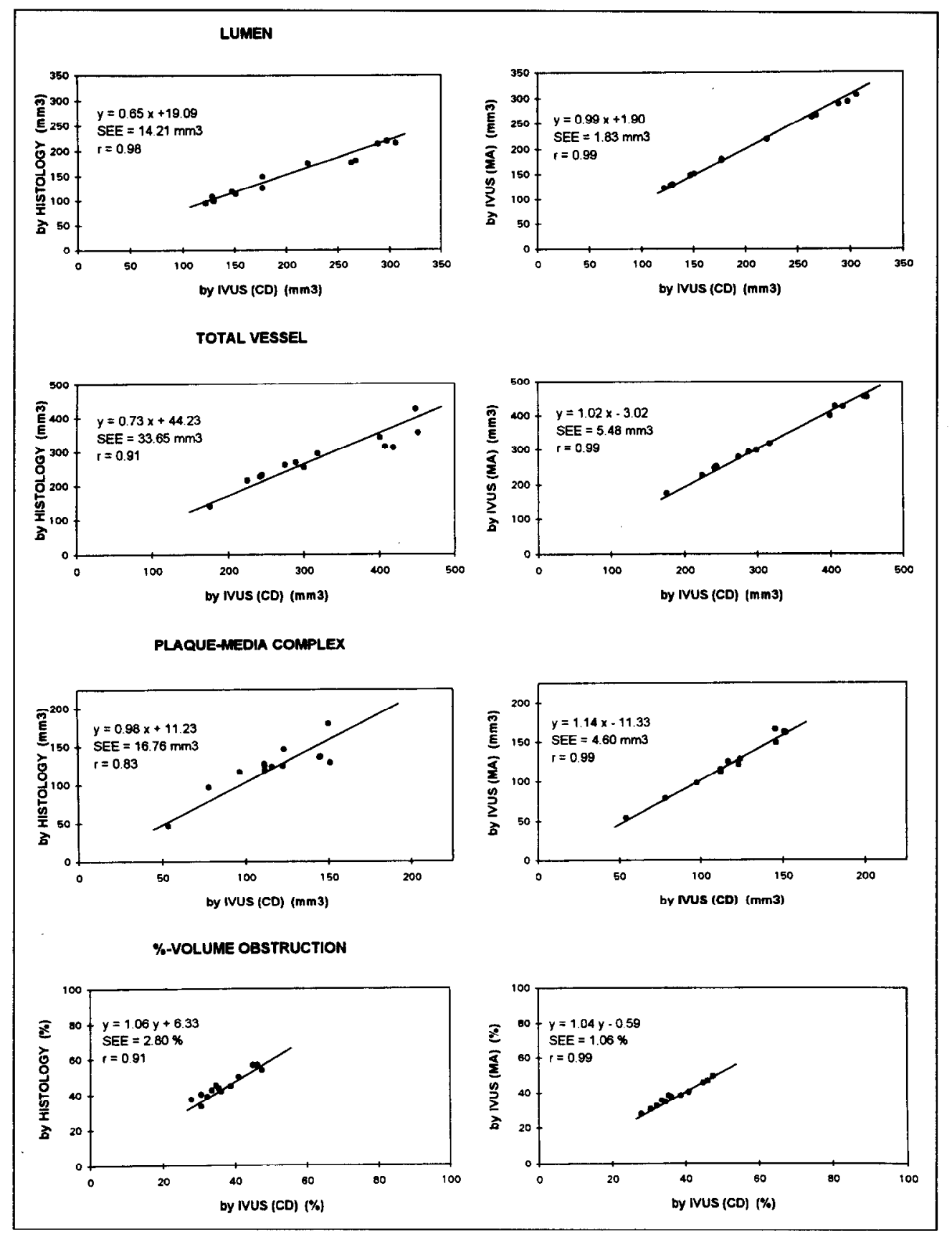

FIGURE 5. Correlations between the volumetric measurements. The results of linear regression analyses are displayed, comparing the measurements of the lumen, total vessel, plaque-media complex, and percent volume obstruction provided by the computerized contour detection (CD) method and manual tracing (MA) on the intravascular ultrasound (IVUS) images (right panels), and morphometry on the histologic sections (left panels).

Previous studies: The high correlations between measurements on the cross-sectional IVUS images and the corresponding histologic sections observed in the present study are in concordance with previous observations of Potkin et al ${ }^{24}$ who found correlation coefficients of $0.94,0.85$, and 0.84 for total vessel area, lumen area, and percent area obstruction. The measurements by IVUS were smaller for the lumen and larger for the total vessel area. ${ }^{24}$ The effect of tissue shrinkage ${ }^{25}$ and different modalities of tissue fixation and pressurization may account for the differences from previous observations ${ }^{6,19}$ which showed a larger lumen area by IVUS than by histomorphometry. To date only 1 study comparing true volumetric IVUS measurements and histomorphometry has been reported. ${ }^{26}$ Excellent correlations between the computerized threshold-based IVUS analysis of the lumen volume in vivo and measurements based on both manual tracing and histomorphometry were found ( $r=0.97$ for both), confirming the results of the present study $(r=0.99$ and 0.98 , respectively). Comparable data on the total vessel and plaque-media volume were not available, as this threshold-based method was able to detect only the lumen. 
Sonka et $\mathrm{al}^{27}$ devised an alternative approach of contour detection that performs a computerized detection of both the intimal leading edge and the external vessel boundary in IVUS image sequences. In contrast to our analysis system, the automated contour detection on the cross-sectional images is performed without guidance from the additional information provided by contour detection on longitudinally reconstructed IVUS images. ${ }^{15}$ In their study, the correlation between automatic and manual contour tracing on the IVUS images in vitro was $\operatorname{good}^{27}(r=0.91$ and 0.83 for lumen and plaque area, respectively), but slightly lower than the correlation observed in our study.

Study limitations: On IVUS images the external vessel boundary cannot be detected behind calcium owing to acoustic shadowing. The IVUS contour analysis system, however, allows better interpolation of the vessel boundary behind calcium and thus may be more reliable than conventional manual tracing of a single cross-sectional IVUS image. Finally, because there are differences in the velocities of ultrasound in water and blood, the use of water instead of blood in our experimental setup may partly account for an overestimation of the vascular dimensions by IVUS.

Clinical implications: The examination of the coronary arteries by IVUS allows the assessment of atherosclerotic changes ${ }^{6,7,28}$ and the quantification of the progression or regression of atherosclerosis. ${ }^{17}$ To determine the latter, anatomic landmarks such as side branches or spots of calcium can be used to define corresponding IVUS images in serial studies. Our automated approach using the spatial information of the IVUS images acquired during defined transducer pull-back facilitates this process and permits the volumetric assessment of lumen and/or plaque without need for laborious manual analyses. ${ }^{15,16}$ The proposed quantitative IVUS analysis system allows the reproducible ${ }^{16}$ and reliable identification of both the luminal and external vessel boundaries and may thus be used for the routine analysis of IVUS studies, although wedging of the IVUS catheter may slightly increase the variability of preintervention analyses. Cyclic artifacts can be avoided by electrocardiographic-gated image acquisition, ${ }^{29,30}$ which is a prerequisite for on-line application of this analysis system, currently performed in our catheterization laboratory.

1. de Feyter PJ, Serruys PW, Davies MJ, Richardson P, Lubsen J, Oliver MF. Quantitative coronary angiography to measure progression and regression of coronary atherosclerosis: value, limitations, and implications for clinical trials. Circulation 1991;84:412-423.

2. Waters D, Lesperance J, Craven TE, Hudson G, Gillam LD. Advantages and limitations of serial coronary arteriography for the assessment of progression and regression of coronary atherosclerosis. Implications for clinical trials. Circulation 1993;87:II-38-II-47.

3. Fuster V, Badimun L, Badimon JJ, Chesebro JH. The pathogenesis of coronary artery disease and the acute coronary syndromes. $N$ Engl $J$ Med 1992;326:242-250.

4. von Birgelen C, Umans V, Di Mario C, Keane D, Gil R, Prati F, de Feyter PJ, Serruys PW. Mechanism of high-speed rotational atherectomy and ad- junctive balloon angioplasty revisited by quantitative coronary angiography: edge detection versus videodensitometry. Am Heart J 1995; 130:405412.

5. Stiel GM, Stiel LSG, Schofer J, Donath K, Mathey DG. Impact of compensatory enlargement of atherosclerotic coronary arteries on angiographic assessment of coronary artery disease. Circulation 1989;80:1603-1609.

6. Gussenhoven EJ, Essed CE, Lancee CT, Mastik F, Frietman P, van Egmond FC, Reiber J, Bosch H, van Urk, Roelandt J, Bom N. Arterial wall characteristics determined by intravascular ultrasound imaging: an in-vitro study. I Am Coll Cardiol 1989;14:947-952.

7. Ge J, Erbel R, Gerber T, Gorge G, Koch L, Haude M, Meyer J. Intravascular ultrasound imaging in angiographically normal coronary arteries: a prospective study in vivo. Br Heart $J 1994 ; 71: 572-578$.

8. Mintz GS, Painter JA. Pichard AD, Kent KM. Satler LF, Popma JJ, Chuang YC, Bucher TA, Sokolowicz LE, Leon MB. Atherosclerosis in angiographically "normal' coronary artery reference segments: an intravascular ultrasound study with clinical correlations. I Am Coll Cardiol 1995;25:1479-1485.

9. Hausmann D, Lundkvist AJS, Friedrich GJ, Mullen WL, Fitzgerald PJ, Yock PG. Intracoronary ultrasound imaging: intraobserver and interobserver variability of morphometric measurements. Am Heart $J$ 1994; 128:674-680.

10. Rosenfield K, Losordo DW, Ramaswamy K, Pastore JO, Langevin RE Razvi S, Kosowsky BD, Isner JM. Three-dimensional reconstruction of human coronary and peripheral arteries from images recorded during twodimensional intravascular ultrasound examination. Circulation 1991;84:1938-1956.

11. Roelandt JRTC, Di Mario C, Pandian NG, Wenguang Li, Keane D, Slager CJ, de Feyter PJ, Serruys PW. Three-dimensional reconstruction of intracoronary ultrasound images: Rationale, approaches, problems, and directions. Circulation 1994;90:1044-1055.

12. von Birgelen C, Kutryk MJB, Gil R, Ozaki Y, Di Mario C, Roelandt JRTC, de Feyter PJ, Serruys PW. Quantification of the minimal luminal cross-sectional area after coronary stenting by two-dimensional and three-dimensional intravascular ultrasound versus edge detection and videodensitometry. Am J Cardiol 1996:78:520-525.

13. Gil R, von Birgelen C, Prati F, Di Mario C, Ligthart J, Serruys PW. Usefulness of Three-dimensional reconstruction for interpretation and quantitative analysis of intracoronary ultrasound during stent deployment. Am J Cardiol 1996;77:761-764.

i4. von Birgelen C, Gil R, Ruygrok P, Prati F, Di Mario C, van der Giessen WJ, de Feyter PJ, Serruys PW. Optimized expansion of the Wallstent compared to the Palmaz-Schatz stent: on-line observations with two- and three-dimensional intracoronary ultrasound after angiographic guidance. Am Heart $J$ 1996;131:1067-1075.

15. Li W, von Birgelen C, Di Mario C, Boersma E, Gussenhoven EJ, van der Putten N, Bom N. Semi-automatic contour detection for volumetric quantification of intracoronary ultrasound. In: Computers in Cardiology 1994. Los Alamitos, California: IEEE Computer Society Press, 1994:277280 .

16. von Birgelen C, Di Mario C, Li W, Schuurbiers JCH, Slager CJ, de Feyter PJ, Roelandt JRTC, Serruys PW. Morphometric analysis in threedimensional intracoronary ultrasound: an in-vitro and in-vivo study using a novel system for the contour detection of lumen and plaque. Am Heart $J$ (in press)

17. von Birgelen C, Slager CJ, Di Mario C, de Feyter PJ, Serruys PW. Volumetric intracoronary ultrasound: a new maximum confidence approach for the quantitative assessment of progression-regression of atherosclerosis? Atherasclerosis 1996;118(suppl):S103-S113.

18. Hong MK, Mintz GS, Popma JJ, Kent KM, Pichard AD, Satler LF, Leon MB. Limitations of angiography for analyzing coronary atherosclerosis progression or regression. Ann Intern Med 1994;121:348-354.

19. Matar FA, Mintz GS, Farb A, Douek P, Pichard AD, Kent KM, Satler LF, Popma JJ, Keller MB, Pinnow E, Merritt AJ, Lindsay J Jr, Leon MB. The contribution of tissue removal to lumen improvement after directional coronary atherectomy. Am J Cardiol 1994;74:647-650.

20. Dussaillant GR, Mintz GS, Pichard AD, Kent KM, Satler LF, Popma JJ, Wong SC, Lcon MD. Small stent size and intimal hyperplasia contribute to restenosis: a volumetric intravascular ultrasound analysis. J Am Coll Cardiol 1995;26:720-724.

21. van der Lugt A, Gussenhoven EJ, Stijnen $T$, van Strijen $M$, van Driel E, van Egmond FC, van Suylen RJ, van Urk H. Comparison of intravascular ultrasonic findings after coronary balloon angioplasty evaluated in vitro with histology. Am J Cardiol 1995;76:661-666.

22. Di Mario C, The SHK, Madretsma S, van Suylen RJ, Wilson RA, Bom N, Serruys PW, Gussenhoven EJ, Roelandt JRTC. Detection and characterization of vascular lesions by intravascular ultrasound: an in vitro study correlated with histology. J Am Soc Echocardiogr 1992;5:135-146.

23. Bland JM, Altman DG. Statistical methods for assessing agreement between two methods of clinical measurement. Lancet 1986;2:307-310.

24. Potkin NN, Bartorelli AL, Gessert JM, Neville RF, Aluragor Y, Roberts WC, Leon MB. Coronary artery imaging with intravascular high-frequency ultrasound. Circulation 1990;81:1575-1585.

25. Siegel RJ, Swan K, Edwards G, Fishbein MC. Limitations of postmortem assessment of human coronary artery size and luminal narrowing: differential 
effects of tissue fixation and processing on vessels with different degrees of atherosclerosis. J Am Coll Cardiol 1985;75:452-460.

26. Matar FA, Mintz GS, Douek P, Farb A, Virmani R, Saturnino PJ, Popma

JJ, Pichard AD, Kent KM, Satler LF, Keller M, Leon MB. Coronary artery lumen volume measurement using three-dimensional intravascular ultrasound: validation of a new technique. Cathet Cardiovasc Diagn 1994;33: 214-220.

27. Sonka M, Zhang X, Siebes M, DeJong S, McKay CR, Collins SM. Automated segmentation of coronary wall and plaque from intravascular ultrasound image sequences. In: Computers in Cardiology 1994. Los Alamitos: IEEE Computer Society Press, 1994:281-284.
28. Ge J, Erbel R, Zamorano J, Koch L, Kearney P, Gorge G, Gerber T, Meyer $\mathrm{J}$. Coronary artery remodeling in atherosclerotic disease: an intravascular ultrasonic study in vivo. Coron Artery Dis 1993;4:981-986.

29. Dhawale PJ, Wilson DL, Hodgson JM. Optimal data acquisition for volumetric intracoronary ultrasound. Cathet Cardiovasc Diagn 1994;32:288-299.

30. Bruining N, von Birgelen C, Di Mario C, Prati F, Li W, Den Hood W, Patijn M, de Feyter PJ, Serruys PW, Roelandt JRTC. Dynamic three-dimensional reconstruction of ICUS images based on an ECG-gated pull-back device. In: Computers in Cardiology 1995. Los Alamitos, CA: IEEE Computer Society Press, 1995:633-636. 